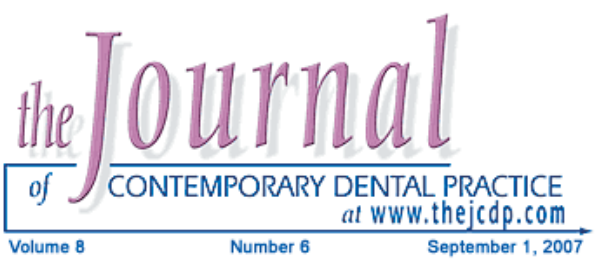

\title{
The Influence of Temperature on the Efficacy of Polymerization of Composite Resin
}

\section{Wedad Y. Awliya, BDS, MSc}

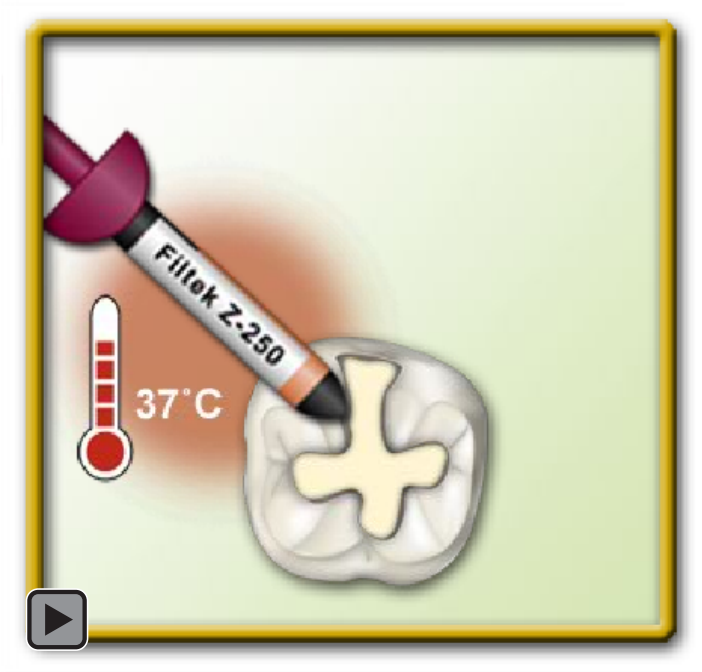

Abstract

Aim: The purpose of this study was to investigate the effect of different temperatures on the efficacy of polymerization during the insertion of composite resin using different light curing units.

Methods and Materials: A total of 45 disc-shaped specimens were fabricated from $Z 250$ composite resin (3M/ESPE, St. Paul, MN, USA) with 15 each prepared at three different temperatures (refrigerated to $5^{\circ} \mathrm{C}$, room temperature at $25^{\circ} \mathrm{C}$, and preheated to $37^{\circ} \mathrm{C}$ ). Each of these temperature-controlled specimen groups of 15 were then subdivided into three groups of five specimens, according to the type of curing light used to polymerize them. Curing lights included a conventional halogen light (QTH) in two modes (continuous and softstart polymerization) and a light emitting diode (LED). The microhardness of the top and bottom surfaces of the specimens was determined using a Buehler Micromet II digital microhardness tester (Buehler, Dusseldorf, Germany). Data obtained was analyzed using two-way analysis of variance (ANOVA)/Post Hoc Tukey's test at a 0.05 significance level.

Results: As the temperature of composite resin increased, the top and bottom microhardness of the specimens also increased regardless of the type of polymerizing light used. The LED light produced a significantly better hardness on top and bottom surfaces of composite resin specimens polymerized at the three different temperatures. Effectiveness of cure at top and bottom surfaces of composite specimens was significantly reduced by using soft-start curing.

๑) Seer Publishing 
Conclusion: The use of pre-warmed composite resins might help to improve polymerization of composite resin especially at the deeper areas of a restoration which could result in an increase in the expected life of a composite restoration.

Keywords: Composite resin restorations, microhardness, curing lights, composite resin temperature

Citation: Awliya WY. The Influence of Temperature on the Efficacy of Polymerization of Composite Resin. J Contemp Dent Pract 2007 September; (8)6:009-016.

\section{Introduction}

Along with the advancement of composite resin materials, light sources and light curing techniques for composite resins have improved remarkably. Light-emitting diodes (LEDs) have been introduced for curing dental composite and to overcome drawbacks of the conventional quartz-tungsten halogen lights (QTH) such as: the temperature increase during polymerization which might affect pulp vitality and the progressive degradation of the performance of the bulb which might affect the physical properties of the restoration. ${ }^{1,2}$ A LED light emits a narrow spectrum of light at $(450-500 \mathrm{~nm})$ with a peak close to the peak of absorption of camphoroquinone, which is the most common photoinitiator used in dental composites (470 $\mathrm{nm}) .^{3}$ Therefore, no filter is required as with QTH lights which emit a wide spectrum of light. ${ }^{4,5}$

High intensity light sources have reportedly improved the immediate depth of cure as well as the physical and mechanical properties of composite restorations. ${ }^{6,7}$ However, their use has been reported to result in high polymerization shrinkage stresses. ${ }^{7,8}$

Several curing protocols have been suggested to reduce composite shrinkage stress that can disrupt the bond to the cavity wall. The so-called "soft-start polymerization" characterized by using an initial low-power intensity of the curing light followed by higher-power intensity has been advocated to minimize internal stresses in composite and improving its marginal adaptation..$^{9,10}$ This initial low-light intensity could facilitate a certain degree of polymer chain reaction so a portion of shrinkage stress relaxes while the resin reaches its final hardening. ${ }^{11,12}$ Soft-start curing is claimed to partially relieve shrinkage stress and achieves an improved integrity of the composite/tooth interface without compromising the final double-bond conversion or mechanical properties of the cured composite. ${ }^{12}$ However, other studies found the effectiveness of the cure at the bottom surfaces of composite resin was significantly affected when soft-start polymerization regimens were used. ${ }^{13}$

The hardness of composite resin materials is influenced by several factors, such as organic matrix composition, ${ }^{14}$ type of the filler particles, ${ }^{15}$ and degree of conversion. ${ }^{16}$ For many years, dentists were often asked to refrigerate their composite material until immediately before use. Although some studies found no adverse effects from using materials directly from refrigerated storage, ${ }^{17,18}$ others found this to probably be the worse possible course of action. ${ }^{19,20}$ On the other hand, the warming of composites to body temperature, or somewhat higher, immediately before placement has been shown to improve composite properties and reduce curing time. ${ }^{21,22}$ Insertion temperature has been found to have an influence on the hardness of composite. The Vickers' hardness of restorations inserted with the composite resin pre-warmed to 3 degrees warmer than body temperature $\left(40^{\circ} \mathrm{C}\right)$ was found to be significantly harder than the composite resin inserted at room temperature. ${ }^{23}$ Moreover, Trujillo et al. ${ }^{24}$ found an elevated temperature of composite resin during photopolymerization resulted in substantially higher immediate and final conversion values of all composite resin materials tested in their study along with a concomitant improvement in fracture resistance and a $50 \%$ or more reduction in curing time. Holmes et al. ${ }^{25}$ also found the film thickness of microhybrid composite resin decreased by approximately $30 \%$ when the material was heated to $54^{\circ} \mathrm{C}$. Thus, it is possible to use a highly filled pre-warmed packable hybrid composite at gingival margins in a deep restoration while eliminating poor marginal adaptation. 
The aim of this study was to test the effect of different composite resin temperatures (body temperature at $37^{\circ} \mathrm{C}$, refrigerated to $5^{\circ} \mathrm{C}$, and room temperature at $25^{\circ} \mathrm{C}$ ) on the efficacy of polymerization using a conventional QTH curing light in two modes (continuous and soft-start polymerization) and a LED curing light. The effectiveness of cure was assessed by measuring the top and bottom surface hardness of $2 \mathrm{~mm}$ composite specimens after curing.

\section{Methods and Materials}

The material tested in this study was shade A2 of the 3M/ESPE Z250 microhybride restorative composite resin. Specimens of the restorative were fabricated from the material stored at three different temperatures as follows:

1. Refrigerated Z250. The composite material was subdivided into equal small increments and placed in small, well sealed, light-safe containers to prevent temperature variation in the refrigerated group at sample preparation time. These containers were stored in a refrigerator at $5^{\circ} \mathrm{C}$ for 24 hours before sample preparation.

2. Pre-warmed Z250. Other composite resin compoules were pre-warmed to $37^{\circ} \mathrm{C}$ using a Calset Unit 21 composite warming unit (AdDent, Inc., Danbury, CT, USA) in which the compoules are heated to a desired temperature.

3. Room Temperature Z250. More of the composite material was stored at room temperature $\left(25^{\circ} \mathrm{C}\right)$.

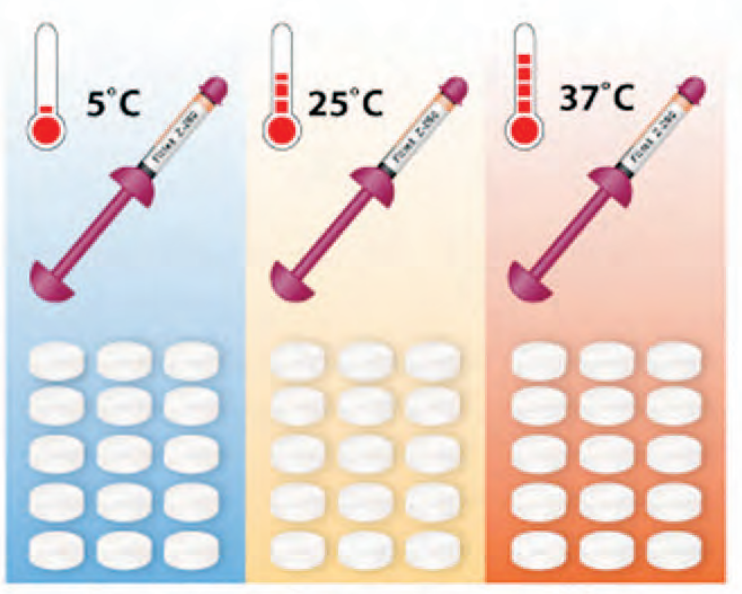

Specimens made with temperature-controlled resin
Fifteen disc specimens for each temperature group of Z250 listed above were then fabricated using silicon Teflon ${ }^{\boxplus}$ mold split rings $(8 \mathrm{~mm}$ internal diameter and $2 \mathrm{~mm}$ thickness). The mold was placed on a transparent matrix strip and glass slide. The restorative material was injected into the mold then the filled mold was covered with a second transparent matrix and light pressure was applied to expel excess material. Five specimens from each temperature group were then polymerized with one of the following lights:

1. Elipar Trilight Conventional QTH light (TL, 3M/ ESPE, Seefeld, Germany) at $700 \mathrm{~mW} / \mathrm{cm}^{2}$ continuous light for 40 seconds.

2. Elipar Trilight Conventional QTH light programmed for soft-start polymerization at $200 \mathrm{~mW} / \mathrm{cm}^{2}$ for 10 seconds followed by 600 $\mathrm{mW} / \mathrm{cm}^{2}$ for 30 seconds.

3. Elipar Freelight II LED light (FE, 3M/ESPE, Seefeld, Germany) at $1000 \mathrm{~mW} / \mathrm{cm}^{2}$ for 20 seconds.

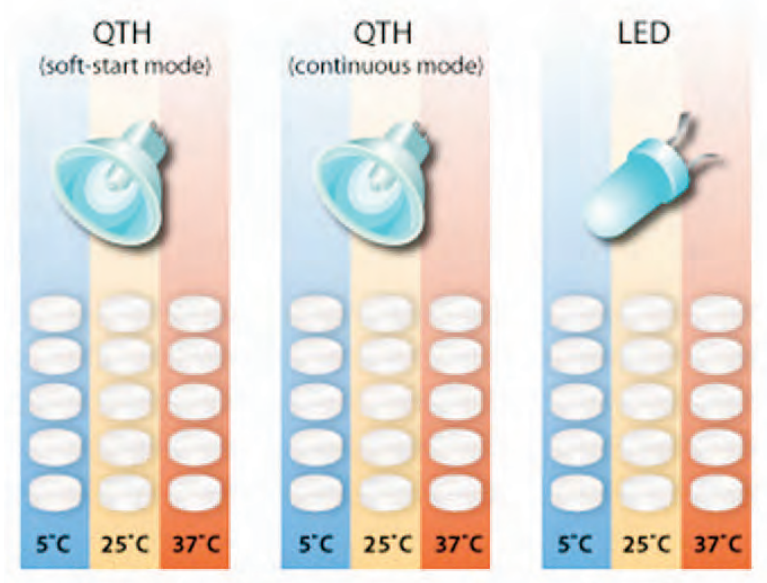

Polymerization of specimens using different curing methods

The light intensity of the curing units was measured using a radiometer before use. The set discs were then separated from the mold, and the excess material was removed with a scalpel blade. All specimens were then immersed in distilled water for 24 hours.

The surface hardness of the specimens was determined using a Buehler Micromet II Digital Microhardness Tester with a Vickers diamond indenter attached. A load of $300 \mathrm{~g}$ was applied to the surface of the specimens for 12 seconds. 


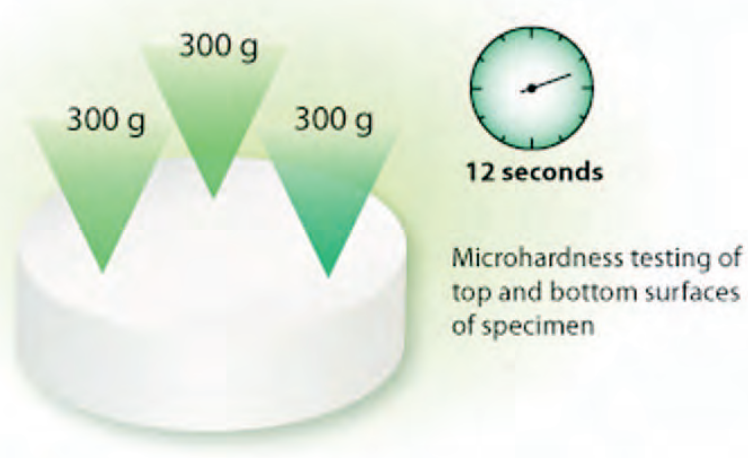

Three indentations equally placed over a circle and not closer than $1 \mathrm{~mm}$ to either adjacent indentations or to the margin of the specimens were made on the surface of each specimen. Data was statistically analyzed using SPSS software (SPSS Inc., Chicago, IL, USA). A two-way analysis of variance (ANOVA) was used to determine any significant difference in the hardness values of the composite resin temperature and the curing method. The Post Hoc Tukey's test at 0.05 significance level was also used to make comparisons between different groups.

\section{Results}

The mean Vickers microhardness values for top and bottom surfaces of the composite specimens resulting from the use of different curing methods on specimens made from composite resin at three different temperatures are summarized in Table 1 and Figures 1 to 3.

The two-way ANOVA revealed significant differences in the hardness values based on composite temperature $(p=0.000)$ and curing method $(p=0.000)$. As composite resin temperature increased, microhardness of the top and bottom of the specimens also increased regardless of the polymerizing light used to cure the material. A LED light produced significantly better hardness values on top and bottom surfaces of the composite resin specimens polymerized at the three different temperatures.

On the other hand, soft-start produced significantly the lowest hardness values on top and bottom surfaces of all specimens. The different lights produced significantly harder top surfaces than bottom surfaces of all samples at the different

Table 1. Mean Vickers hardness values (VHK) and standard deviations (SD) of composite resin specimens at different temperatures.

\begin{tabular}{|c|l|c|c|c|}
\hline Temperature & \multicolumn{1}{|c|}{ Light unit } & Top VHN (SD) & Bottom VHN (SD) & Pvalue \\
\hline \multirow{2}{*}{ Room Temperature } & Soft-start & $70.1(1.1)$ & $61.4(1.7)$ & 0.000 \\
\cline { 2 - 5 } & QTH & $81.2(1.6)$ & $72.4(1.1)$ & 0.011 \\
\cline { 2 - 5 } & LED & $90.6(1.5)$ & $81(1.4)$ & 0.000 \\
\hline Refrigerated to $5^{\circ} \mathrm{C}$ & Soft-start & $57.9(5.6)$ & $55.2(2.7)^{\Delta}$ & $0.350^{*}$ \\
\cline { 2 - 5 } & QTH & $66.2(4.4)$ & $57.6(1.4)^{\Delta}$ & 0.003 \\
\cline { 2 - 5 } & LED & $80.6(1.3)$ & $70.2(5.2)$ & 0.003 \\
\hline Preheated to $37^{\circ} \mathrm{C}$ & Soft-start & $73.7(0.7)$ & $62.3(1.9)$ & 0.006 \\
\cline { 2 - 5 } & QTH & $82.0(1.6)$ & $79.5(2.8)$ & $0.124^{*}$ \\
\cline { 2 - 5 } & LED & $98.2(6.4)$ & $92.9(8.3)$ & $0.287^{*}$ \\
\hline
\end{tabular}

$\Delta$ Indicates means are not significantly different $(P>0.05)$ * Indicates that top and bottom surfaces are not significantly different $(\mathrm{P}>0$.05) $\mathrm{QTH}=$ Conventional Halogen Light. LED= Light emitting Diode 


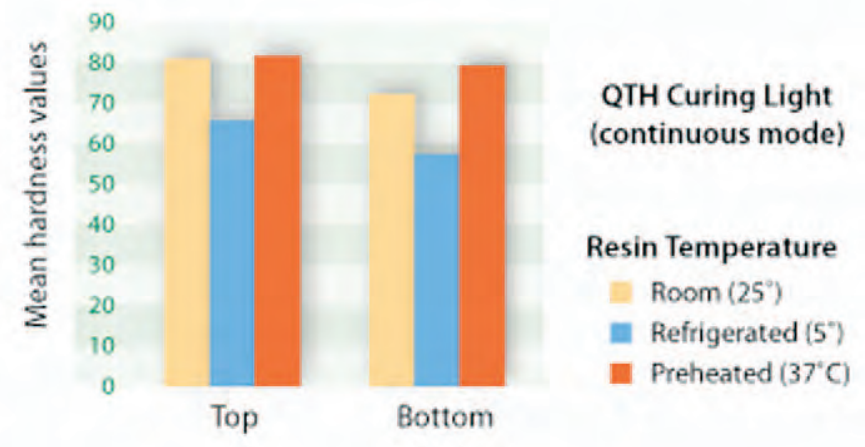

Figure 1. Mean hardness values of composite resin specimens at the different temperatures cured with the QTH light.

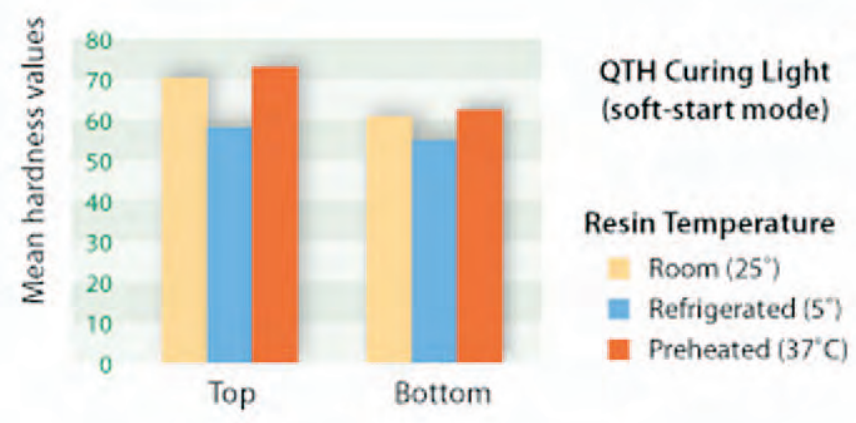

Figure 2. Mean hardness values of composite resin specimens at the different temperatures cured by soft-start polymerization.

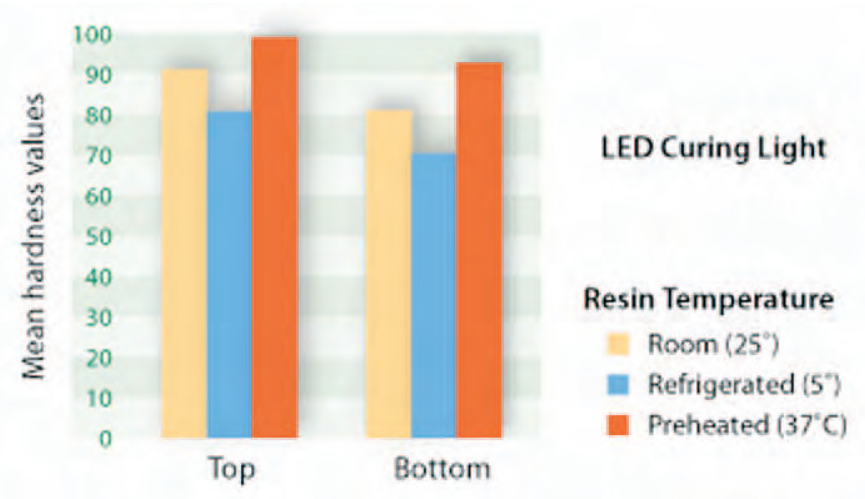

Figure 3. Mean hardness values of composite resin specimens at the different temperatures cured by LED light.

temperatures. However, there was no significant difference in microhardness between top and bottom surfaces of refrigerated composite polymerized with the soft-start technique $(P=0.350)$. Also, no significant difference between top and bottom surfaces of composite resin polymerized was found on composite material cured at $37^{\circ} \mathrm{C}$ using conventional QTH and LED $(P>0.05)$.

\section{Discussion}

The effectiveness of composite cure may be assessed by direct and indirect methods. Direct methods such as Raman laser and infrared spectroscopy are not used routinely as they are complex, expensive, and time consuming. ${ }^{26}$ Indirect methods such as surface hardness are more commonly employed..$^{26,27}$ Hardness is the resistance of material to indentation and it 
correlates well to the material's strength and rigidity. ${ }^{28,29}$ Vickers hardness testing was selected for this study because of its relative simplicity and favorable correlation to the degree of conversion using infrared spectroscopy. ${ }^{26,27}$ Asmussen ${ }^{27}$ and Ferracane ${ }^{16}$ found a correlation between the increase in surface hardness and an increase in the degree of conversion of resin materials. Materials with low surface hardness contain a high amount of unreacted methacrylate groups. ${ }^{30}$

The three light sources used in this study were selected to represent different light intensities that might help to fully cure deeper areas of composite resin specimens at their different temperatures. The best surface hardness (top and bottom) in this study were obtained using pre-warmed composite resin at $37^{\circ} \mathrm{C}$ using the three different curing lights. On the other hand, the lowest surface hardness (top and bottom) resulted from using refrigerated composite resin. Freedman et al. ${ }^{21}$ stated the use of pre-warmed composite resin will enhance the physical properties of the final restoration, reduce polymerization time, and increase the degree of conversion. A substantial increase in the degree of polymerization ${ }^{31}$ and surface hardness ${ }^{32}$ of extraorally fabricated inlays and onlays has been reported when heat curing in addition to visible light curing was used.

Ideally, the degree of polymerization of composite should be the same throughout its depth and the hardness ratio between top and bottom surfaces should be very close or equal to each other. ${ }^{33}$ The results of this study showed refrigerated or room temperature composite resin cured by the different curing lights had significantly lower hardness values on bottom surfaces than top surfaces. Ruyter et al.$^{34}$ found as light passes through the composite the light intensity is greatly reduced due to light scattering which deceases the effectiveness of cure at the bottom surface. Nevertheless, preheated composite resin cured by conventional QTH and LED in this study showed no difference in microhardness between top and bottom surfaces which indicates composite temperature has an influence on its final polymerization. Preheated composite resin cured using the soft-start technique showed significantly higher top and bottom hardness values than composite resin at the other two temperatures cured by the same light. However, these values were significantly lower than the specimens cured by the QTH and LED lights. Regardless of composite resin temperature Yap $^{13}$ found the soft-start polymerization technique may reduce the effectiveness of cure at bottom surfaces of composite resin. Using initially low intensity 200 $\mathrm{mW} / \mathrm{cm}^{2}$ for ten seconds appeared to minimize the compensatory effects of high light intensities. ${ }^{7}$

Polymerization of resin associated with the initial cure may be sufficient to interfere with light transmission and severely decrease the amount of light reaching the bottom surface of composite restorations. ${ }^{7}$ Although the LED light in this study was applied for a shorter time than the QTH light, it was more effective than the conventional QTH curing unit in polymerizing top and bottom surfaces of all composite specimens regardless of their temperatures. This finding is consistent with the findings of previous investigations. ${ }^{35,36,37}$

Halogen light curing units produce a wide spectral emission, including light in the visible spectrum, and then uses filters to eliminate all wavelengths except blue light. ${ }^{4}$ Therefore, some of the emitted photons might be out of the spectrum of absorption of the camphoroquinone photoinitiator and the triplex state of the camphoroquinone might not be fully activated. ${ }^{4}$ On the other hand, LED lights emit a narrow wavelength spectrum and have a specific energy density for camphoroquinone. ${ }^{3}$

A short irradiation time combined with a high, uniform conversion and low stress is desirable in clinical practice. Practitioners are faced with the dilemma of improving the degree of conversion worsens marginal continuity. It must be emphasized energy is attenuated in deeper 
areas of the restoration, thus, full conversion can be at risk. ${ }^{38}$ Therefore, the use of prewarmed composite resin might help improve conversion, especially at the deeper areas of the restoration, which improves its physical properties and reduces its film thickness. Thus, it is possible to use pre-warmed hybrid, or packable composite, at the gingival margin to achieve better marginal adaptation and to attain better and faster conversion in areas where isolation control is not optimal. Finally, elevating composite resin temperature during polymerization will reduce curing time, consequently, saving chair time. A concern might arise regarding the effect of using high temperature composite on the dental pulp causing iatrogenic damage. However, the maximum intrapulpal temperature rise from the application of composite resin heated to $57.2^{\circ} \mathrm{C}$ was approximately $1.6^{\circ} \mathrm{C}$ which is well within the pulp tolerance of more than $10^{\circ} \mathrm{C}^{39}$
Further investigation is needed to study the effect of different composite temperatures on tooth/ restoration marginal integrity using different curing methods.

\section{Conclusion}

Within the limits of the present study the following can be concluded:

- As composite resin temperature increased, the microhardness of the top and bottom of specimens increased regardless of curing light used.

- LED light produced significantly the best microhardness of the top and bottom surfaces of the composite resin specimens polymerized at the three different temperatures and in less time.

- The soft-start polymerization technique produced significantly lower top and bottom surface hardness values of all specimens.

\section{References}

1. Mills RW, Jandt KD, Ashworth SH. Dental composite depth of cure with halogen and blue light emitting diode technology. Br Dent J 1999; 186:388-391.

2. Martin FE. A survey of efficiency of visible light curing units. J Dent 1998; 26:239-243.

3. Hammesfahr PD, O'Connor MT, Wang X. Light curing technology: Past, Present, and Future. Compendium 2002; 23(9):18-24.

4. Burgess Jo, Walker RS, Porche CJ, Rappold AJ. Light curing-An Update. Compend Contin Educ Dent 2002; 23(10):889-892.

5. Kurachi C, Tuboy AM, Magalhães DV, Bagnato VS. Hardness evaluation of a dental composite polymerized with experimental LED-based devices. Dent Mater 2001; 17:309-315.

6. Soh MS, Yap AUJ. Influence of curing modes on crosslink density in polymer structures. J Dent 2004; 32:321-326.

7. Yap AUJ, Seneviratne C. influence of light energy density on effectiveness of composite cure. Oper Dent 2001; 26:460-466.

8. Yap AUJ, Wong NY, Siow KS . Composite cure and shrinkage associated with high intensity curing light. Oper Dent 2003; 28:357-364.

9. Lime BS, Ferracane JL, Sakaguchi RL, Condon JR. Reduction of polymerization contraction stress for dental composites by two-step light activation. Dent Mater 2002; 18:436-444.

10. Hofmann N, Hugo B, Klaiber B. Effect of irradiation type (LED or QTH) on photo-activated composite shrinkage strain kinetics, temperature rise, and hardness. Eur J Oral Sci 2002; 110:471-479.

11. Feilzer AJ, Dooren LH, de Gee AJ, Davidson CL. Influence of light intensity on polymerization shrinkage and integrity of restoration-cavity interface, Eur J Oral Sci 1995; 103:322-326.

12. Sakaguchi RL, Berge HX. Reduced light energy decreases post-gel contraction while maintaining degree of conversion in composites. J Dent 1998; 26:695-700.

13. Yap AUJ, Soh MS, Siow KS . Effectiveness of composite cure with pulse activation and soft start polymerization. Oper Dent 2002; 27:44-49.

14. Asmussen E. Restorative resins: hardness and strength vs. quantity of remaining double bonds. Scand J Dent Res 1982; 90:484-489. 
15. Chung $\mathrm{KH}$, Greener EH. Correlation between degree of conversion, filler concentration and mechanical properties of posterior composite resins. J Oral Rehabil 1990; 17:487-494.

16. Ferracane JL. Correlation between hardness and degree of conversion during the setting reaction of unfilled dental restorative resins. Dent Mater 1985; 1:11 -14.

17. Torre-Moreno FJ, Rosales-Leal JI, Bravo M. Effect of cooled composite inserts in the sealing ability of resin composite restorations placed at intraoral temperatures: an in vitro study. Oper Dent 2003; 28:297-302.

18. Hagge MS, Lindemuth JS, Broome JC. Effect of refrigeration on shear bond strength of three dentine bonding systems. Am J Dent 1999; 12:131-133.

19. Bausch JR, de Lange C, Davidson CL. The influence of temperature on some physical properties of dental composite. J Oral Rehabil 1981; 8:431-439.

20. Burrow MF, Taniguchi Y, Nikaido T, Satoh M, Inai N, Tagami J, Takatsu T. Influence of temperature and relative humidity on early bond strengths to dentin. J Dent 1995; 23:41 -45.

21. Freedman G, Krejci I. Warming up composites. Compendium 2004; 25:371-376.

22. Freedman G, Leinfelder K. Seventh-generation adhesive system. Dent Today 2002; 21:106-111.

23. Bortolotto T, Krejci I. The effect of temperature on hardness of a light-curing composite. J Dent Res 2003; 82 (Special issue A). Abstract 0119.

24. Trujillo M, Stansbury JW. Thermal effects on composite photopolymerization monitored by real-time NIR. J Dent Res 2003; 82 (Special issue A). Abstract 0819.

25. Holmes RG, Blalock JS, Rueggeberg FA. Composite film thickness at various temperatures. J Dent Res 2004; 83 (Special issue A). Abstract 3265.

26. Yap AUJ, Soh MS, Siow KS . Effectiveness of composite cure with pulse activation and soft start polymerization. Oper Dent 2002; 27:44-49.

27. Asmussen E. Factors affecting the quantity of remaining double bonds in restorative resin polymers. Scan Dent J 1982;90:490-496

28. Anusavice KL. Mechanical properties of dental materials in Philip's Science of Dental Materials 10th edition 1996. Philadelphia WB Saunders Co, p 69.

29. De Wald JP, Ferracance JL. A comparison of four modes of evaluating depth of cure of lightactivated composites. J Dent Res 1987; 66:727-730.

30. Dionysopoulos P, Watts DC, Dynamic mechanical properties of an inlay composite. J Dent 1989; 17:140-144.

31. Wendt SL Jr. The effect of heat used as a secondary cure upon the physical properties of three composite resins II. Wear, hardness and color stability. Quintessence Int 1987; 18:351-356.

32. Breeding LC, Dixon DL, Cughman WF. The curing potential of light-activated composite resin luting agents. J Prosthet Dent 1991; 65:512-518.

33. Ruyter IE, Øysae d H. Conversion in different depth of ultraviolet and visible light activated composite materials. Acta Odontol Scand 1982; 40:179-192.

34. Correr AB, Sinhoreti MA, Correr Sobrinho L, Tango RN, Schneider LF, Consani S. Effect of the increase of energy density on knoop hardness of dental composites light-cured by conventional QTH, LED and xenon plasma arc. Braz Dent J 2005; 16(3):218-24.

35. Owens BM. Evaluation of curing performance of light-emitting polymerization units. Gen Dent 2006; 54:17-20.

36. Barghi N, Mc Alister EH. LED and halogen lights: effect of ceramic thickness and shade on curing luting resin. Compend Contin Educ Dent 2003; 24:497-500.

37. Davidson CL, de Gee AJ. Light curing units, polymerization and clinical implications. J Adhes Dent $2000 ; 2: 167-173$.

38. Zach L, Cohen G. Pulp response to externally applied heat. Oral Surg Oral Med Oral Pathol 1965; 19:515-530. 
About the Author

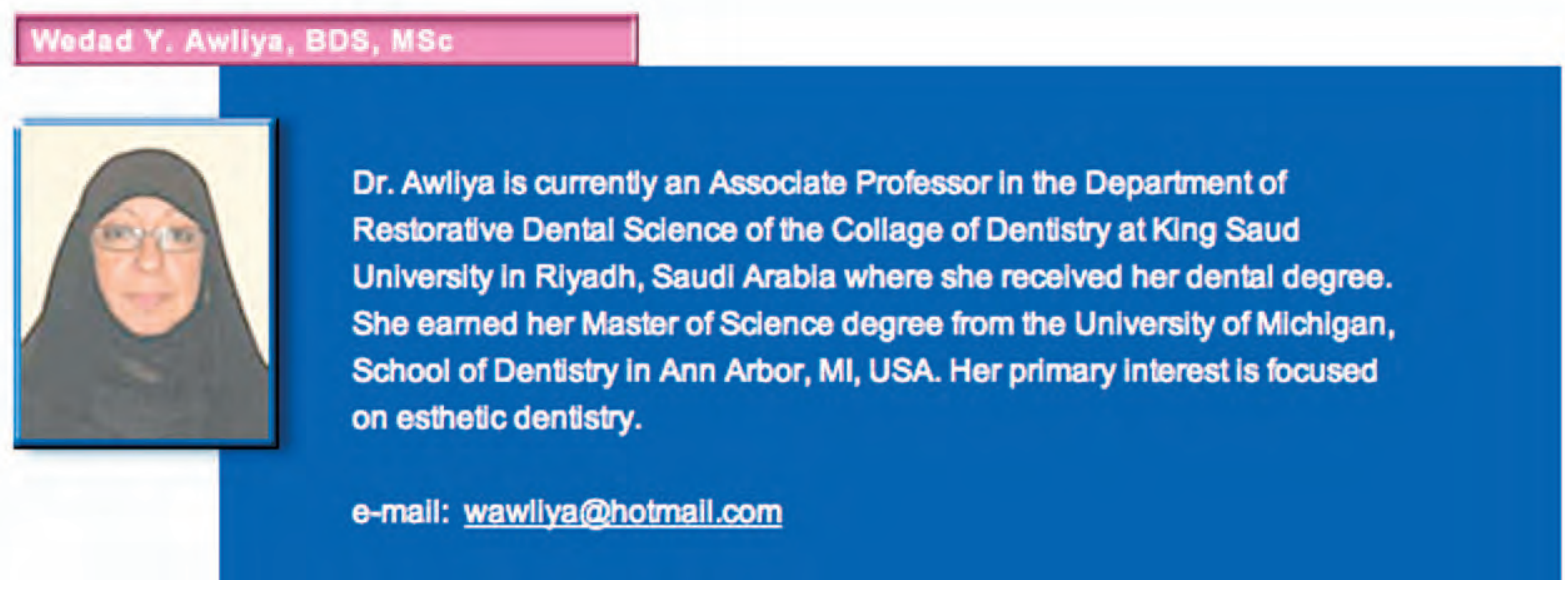

\section{Acknowledgments}

This study was supported by the Women Students Medical and Science Section's Research Center at King Saud University, Grant No: F1138. 